\title{
ANALISA METODE SIMPLE ADDITIVE WEIGHTING (SAW) UNTUK PENENTUAN SMA TERBAIK DI PEMKO MEDAN
}

\author{
Alfonsus Situmorang1), Erika Pakpahan' ${ }^{2)}$ \\ Fakultas Ilmu Komputer - Univ. Methodist Indonesia Medan \\ fonsuss@gmail.com, erika.pakpahan@ymail.com,
}

\begin{abstract}
Abstrak
Persaingan pendidikan dalam beberapa tahun ini semakin pesat. Sekolah berlomba untuk mendapatkan predikat terbaik, sehingga banyak SMA yang bersaing untuk menjadi yang terbaik. Di Pemko Medan sangatlah banyak terdapat tingkat pendidikan SMA sehingga para calon siswa-siswi memerlukan informasi tentang sekolah SMA terbaik untuk tempatnya menempuh pendidikan. Metode Simple Additive Weighting (SAW), merupakan salah saya yang dapat memperoses nilai rangking berdasarkan kriteri. Metode SAW dapat digunakan dalam penentuan alternatif SMA terbaik dengan cara menentukan nilai bobot setiap tingkat pendidikan SMA yang ada di Pemko Medan. Ranking terhadap seluruh tingkat pendidikan SMA di Pemko Medan tersebut dapat dijadikan alternatif informasi oleh masyarakat untuk menentukan pilihan dalam menentukan pendidikan SMA.
\end{abstract}

Kata kunci: Sistem Pendukung Keputusan, SAW, Pemilihan Sekolah SMA

\section{Pendahuluan}

Dinas Pendidikan Pemko Medan memerlukan sistem pendukung keputusan dalam menentukan sekolah terbaik di Pemko Medan agar mempermudah calon siswa-siswi dalam memilih SMA yang diinginkan sesuai dengan kriteria yang dipilih. Terdapat beberapa model dalam Sistem Pendukung Keputusan (SPK), yakni salah satunya adalah Simple Additive Weighting (SAW), karena SAW dapat menentukan nilai bobot untuk setiap atribut. Selanjutnya proses perangkingan yang akan menyelesaikan alternatif terbaik dari sejumlah alternatif. Metode SAW dapat membantu dalam pengambilan keputusan suatu kasus, perhitungan SAW akan menghasilkan nilai yang terbesar hingga terkecil dari sejumlah objek yang diuji.

Metode SAW ini lebih efisien karena waktu yang dibutuhkan dalam perhitungan lebih singkat. Metode SAW membutuhkan proses normalisasi matriks keputusan (X) ke suatu skala yang dapat diperbandingkan dengan semua rating alternatif yang ada. Hal ini disebabkan konsepnya sederhana dan mudah dipahami. Adapun kriteria-kriteria untuk menjadikan sekolah terbaik dilihat dari komponen: nilai akreditasi, jumlah peminat, jumlah siswa-siswi, nilai rata-rata UN, jumlah guru, jumlah tingkat berpendidikan guru (D3), jumlah tingkat berpendidikan guru (S1), jumlah tingkat berpendidikan guru (S2), jumlah guru bersertifikasi, jumlah buku perpustakaan, fasilitas sekolah, dan jumlah alumni (PTN).

\section{Metode Penelitian}

Metode dalam penelitian ini adalah dilakukan dengan menentukan atribut kriteria SMA yang digunakan dan diproses dengan metode SAW, perancangan dan rekayasa sistem, dan pengujian sistem terhadap komponen atribut dalam penentuan SMA Terbaik.

\subsection{Perhitungan SAW}

Adapun tahapan penyelesaian dalam metode SAW (Simple Additive Weighting):

1. Menentukan alternatif yaitu $A_{i}$

2. Menentukan kriteria yang akan dijadikan acuan dalam pengambil keputusan yaitu $C_{i}$

3. Memberikan nilai rating kecocokan setiap alternatif pada setiap kriteria.

4. Menentukan bobot preferensi atau tingkat kepentingan (W) setiap kriteria, terdapat pada Rumus 2.1. $\mathrm{W}=\left[\begin{array}{llllll}W_{1} & W_{2} & W_{3} & \ldots \ldots & \ldots & W_{j}\end{array}\right.$

5. Membuat tabel ranting kecocokan dari setiap alternatif pada setiap kriteria. 
6. Membuat matrik keputusan (X) yang dibentuk dari tabel rating kecocokan dari setiap alternatif pada setiap kriteria. Nilai X setiap alternatif $\left(A_{i}\right)$ pada setiap kriteria $\left(C_{i}\right)$ yang sudah ditentukan, dimana $\mathrm{i}=1,2, \ldots \mathrm{m}$ dan $\mathrm{j}=1,2, . . \mathrm{n}$.

7. Melakukan normalisasi matrik keputusan dengan cara menghitung nilai ranting kinerja ternormalisasi $\mathbf{r}_{\mathbf{i j}}$ dari alternatif $\left(A_{i}\right)$ pada kriteria $\left(C_{i}\right)$ terdapat pada :

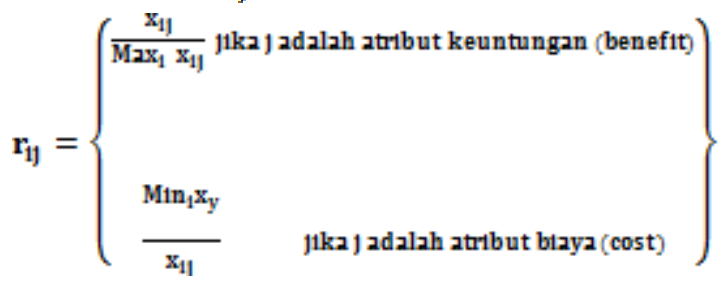

Keterangan:

a. Dikatakan kriteria keuntungan apabila nilai $\mathbf{x}_{\mathrm{ij}}$ memberikan keuntungan bagi pengambil keputusan, maka sebaliknya kriteria biaya apabila $\mathbf{x}_{\mathrm{ij}}$ menimbulkan biaya bagi pengambil keputusan.

b. Apabila berupa kriteria keuntungan maka nilai $\mathbf{x}_{\mathbf{i j}}$ dibagi dengan nilai $\mathbf{M a x}_{\mathbf{i}}\left(\mathbf{x}_{\mathbf{i j}}\right)$ dari setiap kolom, sedangkan untuk kriteria biaya, nilai $\mathbf{M i n n}_{\mathbf{i}}\left(\mathbf{x}_{\mathbf{i j}}\right)$ dari setiap kolom dibagi dengan nilai $\mathbf{x}_{\mathrm{ij}}$.

c. Benefit merupakan nilai terbesar adalah terbaik

d. Cost merupakan nilai terkecil adalah terbaik.

e. $x_{i j}$ merupakan nilai atribut yang dimiliki dari setiap criteria

f. $\operatorname{Max} x_{i j}$ merupakan nilai terbesar dari setiap kriteria

g. $\operatorname{Min} x_{i j}$ merupakan nilai terkecil dari setiap kriteria

Dengan $r_{i j}$ adalah ranting kinerja ternormalisasi dari alternatif $A_{i}$ pada atribut $C_{j} ; \mathrm{i}=1,2, \ldots, \mathrm{m}$ dan $\mathrm{j}=1,2, \ldots \mathrm{n}$

8. Hasil dari nilai rating kinera ternormalisasi $r_{i j}$ membentuk matrik ternormalisai (R) :

$$
R=\left[\begin{array}{lll}
r_{11} & r_{12} & r_{13} \\
- & & - \\
- & & - \\
r_{21} & r_{22} & r_{i j}
\end{array}\right]
$$

9. Hasil akhir nilai preferensi $V_{i}$ diperoleh dari penjumlahan dari perkalian elemen baris matrik ternormalisasi (R) dengan bobot preferensi (W) yang sesuai dengan elemen elemen kolom matrik (W). Hasil perhitungan nilai $V_{i}$ yang lebih besar mengindikasikan bahwa alternatif $A_{i}$ merupakan alternatif tebaik (Kusumadewi, 2006), terdapat pada Rumus 2.4.

$$
V_{i}=\sum_{j=1}^{n} w_{j} r_{i j}
$$

Keterangan:

$$
\begin{aligned}
& V_{1}=\text { rangkaian untuk setiap alternatif } \\
& w_{j}=\text { nilai bobot dari setiap kriteria } \\
& r_{i j}=\text { nilai rating kinerja ternormalisasi }
\end{aligned}
$$




\section{Hasil dan Pembahasan}

\subsection{Rancangan Tabel Kriteria}

Analisa dan rancangan sistem yang digunakan sebagai salah satu satu metode yang dapat memberikan referensi dalam mengembil keputusan sebagai penentuan sekolah terbaik di Pemko Medan. Pada analisa ini diuraikan dengan jelas mengenai perancangan model sistem dan menganalisa prioritas penentuan sekolah terbaik dengan menggunakan metode Simple Additive Weighting (SAW).

Tabel 1. Pembuatan Kriteria

\begin{tabular}{|c|c|l|}
\hline No & Kriteria & \multicolumn{1}{|c|}{ Keterangan } \\
\hline 1 & C1 & Nilai Akreditasi \\
\hline 2 & C2 & Jumlah Peminat \\
\hline 3 & C3 & Jumlah Siswa-siswi \\
\hline 4 & C4 & Nilai rata-rata UN \\
\hline 5 & C5 & Jumlah Guru \\
\hline 6 & C6 & Jumlah Tingkat Pendidikan Guru (D3) \\
\hline 7 & C7 & Jumlah Tingkat Pendidikan Guru (S1) \\
\hline 8 & C8 & Jumlah Tingkat Pendidikan Guru (S2) \\
\hline 9 & C9 & Jumlah Guru Sertifikasi \\
\hline 10 & C10 & Jumlah Buku Perpustakaan \\
\hline 11 & C11 & Fasilitas Sekolah \\
\hline 12 & C12 & Jumlah Alumni (PTN) \\
\hline
\end{tabular}

Tabel 2 Nilai Akreditasi

\begin{tabular}{|c|c|c|}
\hline Kriteria & Bobot & Range \\
\hline \multirow{4}{*}{ C1 } & 4 & $\mathrm{~A}$ \\
\cline { 2 - 3 } & 3 & $\mathrm{~B}$ \\
\cline { 2 - 3 } & 2 & $\mathrm{C}$ \\
\cline { 2 - 3 } & 1 & $\mathrm{D}$ \\
\hline
\end{tabular}

Tabel 3. Jumlah Peminat

\begin{tabular}{|c|c|c|}
\hline Kriteria & Bobot & Range \\
\hline \multirow{4}{*}{ C2 } & 5 & $>=1099$ \\
\cline { 2 - 3 } & 4 & $>=990$ \\
\cline { 2 - 3 } & 3 & $>=881$ \\
\cline { 2 - 3 } & 2 & $>=771$ \\
\cline { 2 - 3 } & 1 & $<771$ \\
\hline
\end{tabular}

Tabel 4. Jumlah Siswa

\begin{tabular}{|c|c|c|}
\hline Kriteria & Bobot & Range \\
\hline \multirow{4}{*}{ C3 } & 5 & $>=660$ \\
\cline { 2 - 3 } & 4 & $>=512$ \\
\cline { 2 - 3 } & 3 & $>=363$ \\
\cline { 2 - 3 } & 2 & $>=214$ \\
\cline { 2 - 3 } & 1 & $<214$ \\
\hline
\end{tabular}

Tabel 5. Nilai Rata-Rata UN

\begin{tabular}{|c|c|c|}
\hline Kriteria & Bobot & Range \\
\hline \multirow{4}{*}{ C4 } & 5 & $>=9,94$ \\
\cline { 2 - 3 } & 4 & $>=8,94$ \\
\cline { 2 - 3 } & 3 & $>=7,94$ \\
\cline { 2 - 3 } & 2 & $>=6$ \\
\cline { 2 - 3 } & 1 & $<6$ \\
\hline
\end{tabular}

Tabel 12. Fasilitas Sekolah

\begin{tabular}{|c|c|c|}
\hline Kriteria & Bobot & Kondisi \\
\hline \multirow{3}{*}{ C11 } & 3 & Sangat memadai \\
\cline { 2 - 3 } & 2 & Memadai \\
\cline { 2 - 3 } & 1 & Cukup Memadai \\
\hline
\end{tabular}

Tabel 6. Jumlah Guru

\begin{tabular}{|c|c|c|}
\hline Kriteria & Bobot & Range \\
\hline \multirow{4}{*}{ C5 } & 5 & $>=50$ \\
\cline { 2 - 3 } & 4 & $>=40$ \\
\cline { 2 - 3 } & 3 & $>=30$ \\
\cline { 2 - 3 } & 2 & $>=20$ \\
\cline { 2 - 3 } & 1 & $<20$ \\
\hline
\end{tabular}

Tabel 7. Jumlah Guru Pendidikan D3

\begin{tabular}{|c|c|c|}
\hline Kriteria & Bobot & Range \\
\hline \multirow{4}{*}{ C6 } & 5 & $>=8$ \\
\cline { 2 - 3 } & 4 & $>=6$ \\
\cline { 2 - 3 } & 3 & $>=4$ \\
\cline { 2 - 3 } & 2 & $>=1$ \\
\cline { 2 - 3 } & &
\end{tabular}

Tabel 8. Jumlah Guru Pendidikan S1

\begin{tabular}{|c|c|c|}
\hline Kriteria & Bobot & Range \\
\hline \multirow{4}{*}{ C7 } & 5 & $>=40$ \\
\cline { 2 - 3 } & 4 & $>=35$ \\
\cline { 2 - 3 } & 3 & $>=25$ \\
\cline { 2 - 3 } & 2 & $>=10$ \\
\hline
\end{tabular}

Tabel 9. Jumlah Guru Pendidikan S2

\begin{tabular}{|c|c|c|}
\hline Kriteria & Bobot & Range \\
\hline \multirow{4}{*}{ C8 } & 5 & $>=10$ \\
\cline { 2 - 3 } & 4 & $>=8$ \\
\cline { 2 - 3 } & 3 & $>=6$ \\
\cline { 2 - 3 } & 2 & $>=4$ \\
\cline { 2 - 3 } & 1 & $<4$ \\
\hline
\end{tabular}

Tabel 10. Jumlah Buku Perpustakaan

\begin{tabular}{|c|c|c|}
\hline Kriteria & Bobot & Range \\
\hline \multirow{4}{*}{ C9 } & 5 & $>=5000$ \\
\cline { 2 - 3 } & 4 & $>=4000$ \\
\cline { 2 - 3 } & 3 & $>=3000$ \\
\cline { 2 - 3 } & 2 & $>=2000$ \\
\hline
\end{tabular}

Tabel 11. Jumlah Buku Perpustakaan

\begin{tabular}{|c|c|c|}
\hline Kriteria & Bobot & Range \\
\hline \multirow{4}{*}{ C10 } & 5 & $>=5000$ \\
\cline { 2 - 3 } & 4 & $>=4000$ \\
\cline { 2 - 3 } & 3 & $>=3000$ \\
\cline { 2 - 3 } & 2 & $>=2000$ \\
\cline { 2 - 3 } & 1 & $<=2000$ \\
\hline
\end{tabular}

Tabel 13. Jumlah Alumni Lulus PTN

\begin{tabular}{|c|c|c|}
\hline Kriteria & Bobot & Range \\
\hline \multirow{4}{*}{ C12 } & 5 & $>=80$ \\
\cline { 2 - 3 } & 4 & $>=60$ \\
\cline { 2 - 3 } & 3 & $>=40$ \\
\cline { 2 - 3 } & 2 & $>=20$ \\
\cline { 2 - 3 } & 1 & $<=20$ \\
\hline
\end{tabular}




\subsection{Rancangan dan Hasil Program}

Perencanaan sistem dapat diartikan sebgai usaha menggabungkan antara modul-modul kegiatan yang saling berkaitan untuk menghasilkan suatu aplikasi sistem program yang outputnya dimungkinkan dapat digunakan untuk angka pendek dan jangka panjang. Diagram konteks merupakan bagan yang menjelaskan secara umum untuk merancang sistem pendukung keputusan. Dari DFD aliran data di diagram konteksnya terlihat seperti gambar 1 .

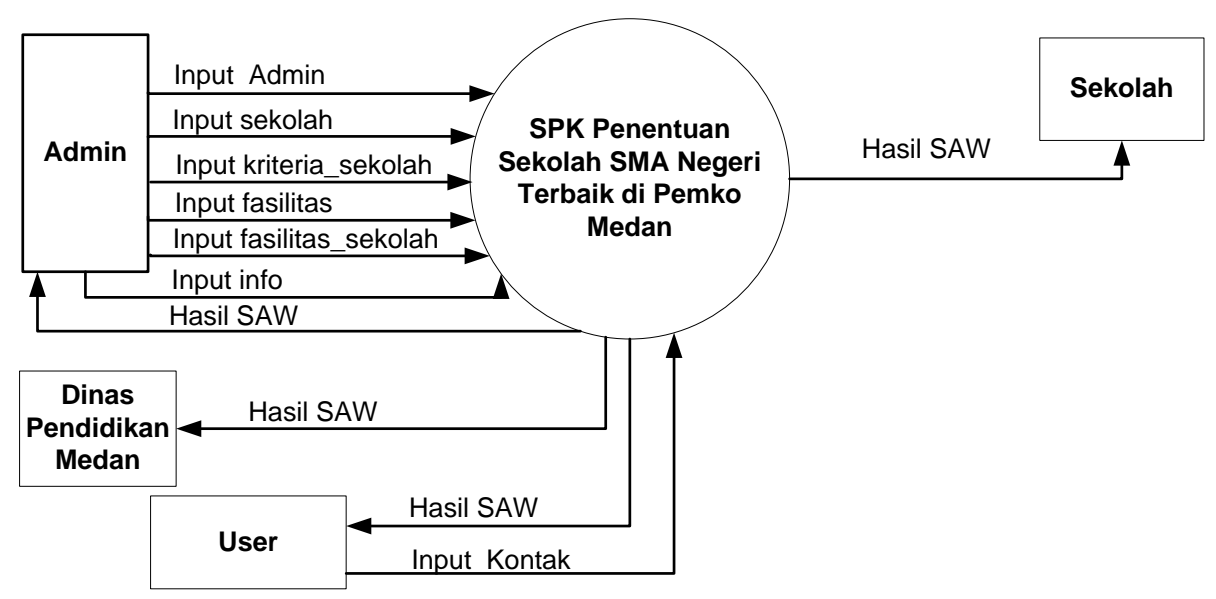

Gambar 1. Diagram Konteks “SPK Penentuan SMA Terbaik di Pemko Medan”.

Tahap implementasi sistem merupakan tahap lanjutan dari perancangan sistem yang dilakukan. Program yang telah dibuat agar siap untuk dioperasikan secara optimal sesuai dengan kebutuhan. Hasil rancangan sistem dengan menggunakan tools PHP dan Database MySQL, diperoleh dengan tampilan gambar 2 dan gambar 3 .

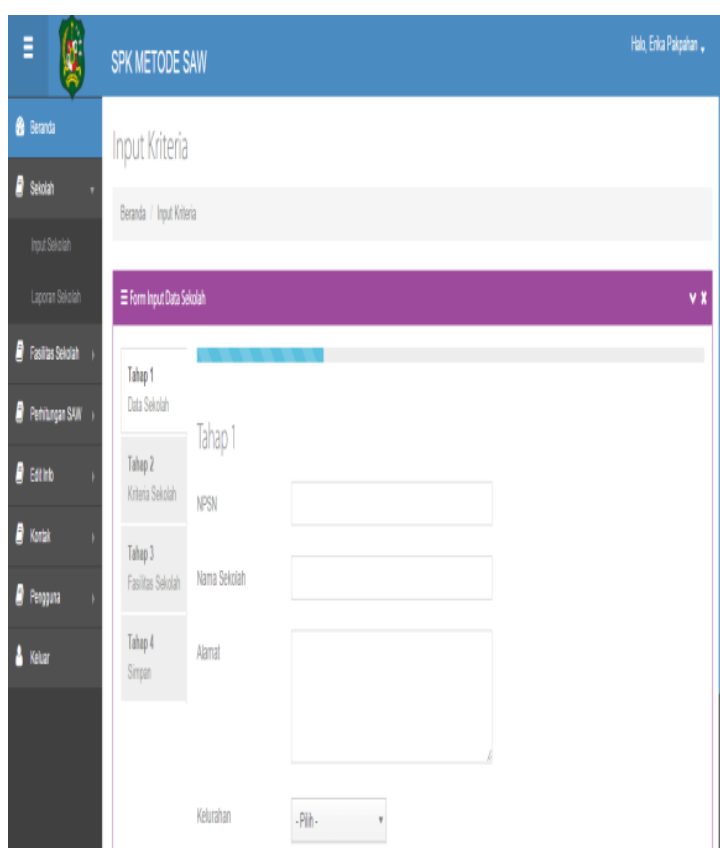

Gambar 2. Tampilan Form Input Data
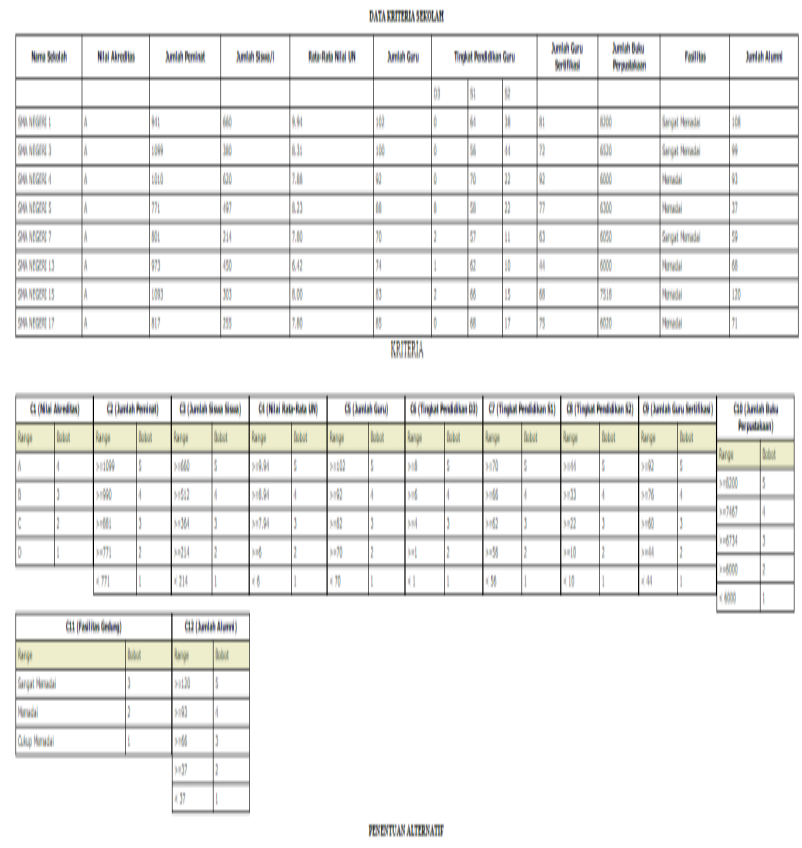

Gambar 3. Tampilan Laporan Hasil 


\section{Penutup}

Pembuatan sistem pengambilan keputusan penentuan SMA terbaik di Pemko, merupakan salah satu alternatif yang dapat menghasilkan informasi pengolahan data SMA di Pemko Medan berdasarkan kriteria-kriteria yang telah di konversikan. Pengolahan data dengan menggunakan metode SAW, lebih memberikan hasil berdasarkan nilai kebenaran kriteri yang di input pada sistem. Hasil akhir dapat digunakan sebagai pertimbangan bagi stakeholder yang membutuhkan informasi tentang SMA di lingkungan Pemko Medan.

\section{Daftar Pustaka}

[1] Arif, M. Rudianto. Pemrograman Web Dinamis Menggunakan PHP dan Mysql. Yogyakarta: ANDI. 2011.

[2] Dwi Citra Hartini,dkk, "Sistem Pendukung Keputusan Pemilihan Hotel Di Kota Palembang Dengan Metode Simple Additive Weighting (SAW)", Jurnal Sistem Informasi (JSI), Vol 5 No.1,April 2013.

[] Kusmawan, "Sistem Pendukung Keputusan Penilaian Hasil Visitasi Support Area Dengan Menggunakan Metode Simple Additive Weighting”. Jurnal LINK ed. Sept. Fakultas Ilmu Komputer Universitas Narotama Surabaya, 2013.

[3] Sri Kusumadewi. Fuzzy Multi-Attribute Decision Making (Fuzzy MADM). Graha Ilmu: Yogyakarta. 2008. 